\title{
Antihypertensive treatment improves left ventricular diastolic function in patients with chronic kidney disease
}

\author{
KU-LIN LI ${ }^{1}$, RU-XING WANG ${ }^{2}$, MIN DAI $^{2}$, JUAN LU $^{2}$, JING XUE $^{3}$ and XIANG-JUN YANG ${ }^{1}$ \\ ${ }^{1}$ Department of Cardiology, First Affiliated Hospital of Soochow University, Suzhou, Jiangsu 215006; \\ Departments of ${ }^{2}$ Cardiology and ${ }^{3}$ Nephrology, Wuxi People's Hospital Affiliated to Nanjing Medical University, \\ Wuxi, Jiangsu 214002, P.R. China
}

Received June 2, 2014; Accepted January 26, 2015

DOI: $10.3892 /$ etm.2015.2322

\begin{abstract}
In patients with chronic kidney disease (CKD), hypertension (HP) is associated with the development of left ventricular (LV) diastolic dysfunction. However, the impact of antihypertensive treatment on LV diastolic function has not been well studied in CKD patients. Recently, two-dimensional speckle-tracking echocardiography (2DSTE) has emerged as a sensitive and quantitative assessment of LV diastolic function. The present study used 2DSTE to investigate the effects of antihypertensive treatment on LV diastolic function in patients with CKD and untreated HP. The study comprised 134 patients with CKD and untreated HP. The patients received blood pressure (BP)-lowering therapy for six months. The patients were clinically and echocardiographically evaluated at baseline and after 6 months of therapy. It was found that the mean systolic BP (SBP) and diastolic BP (DBP) at baseline were $154.0 \pm 7.0$ and $92.6 \pm 10.2 \mathrm{mmHg}$, respectively, decreasing to $121.2 \pm 7.3$ and $74.6 \pm 10.4 \mathrm{mmHg}$, respectively $(\mathrm{P}<0.05$ for both) after the 6-month treatment period. Moreover, the mean peak LV strain rate during the isovolumetric relaxation period $\left(\mathrm{SR}_{\mathrm{IVR}}\right)$ and early diastole $\left(\mathrm{SR}_{\mathrm{E}}\right)$ improved following treatment (from $0.23 \pm 0.10$ to $0.42 \pm 0.10 \mathrm{sec}^{-1}$ and from $0.58 \pm 0.25$ to $1.07 \pm 0.24 \mathrm{sec}^{-1}$, respectively; $\mathrm{P}<0.05$ for both). Notably, the patients with CKD stage $\geq 3$ were more likely to demonstrate an improvement in diastolic speckle-tracking parameters than those with CKD stage 1 or 2 . For the entire population, the change $(\Delta)$ in B-type natriuretic peptide (BNP) level correlated with changes in echocardiographic parameters between baseline and follow-up, among which $\Delta \mathrm{SR}_{\mathrm{IVR}}$ presented the highest correlation coefficient $(\mathrm{r}=-0.73, \mathrm{P}<0.01)$. On multivariate analysis, the independent predictors of $\Delta \mathrm{SR}_{\mathrm{IVR}}$ were found to include baseline CKD stage, $\mathrm{SBP}$ and $\mathrm{SR}_{\mathrm{IVR}}$. This study
\end{abstract}

Correspondence to: Dr Xiang-Jun Yang, Department of Cardiology, First Affiliated Hospital of Soochow University, 188 Shi Zi Street, Suzhou, Jiangsu 215006, P.R. China

E-mail: yangxjjs@126.com

Key words: antihypertensive therapy, diastolic dysfunction-speckle tracking echocardiography, chronic kidney disease demonstrated that $\mathrm{LV}$ diastolic function was improved in CKD patients following antihypertensive treatment, particularly in patients with CKD stage $\geq 3$, higher baseline SBP and worse LV diastolic function. These results highlight the importance of $\mathrm{BP}$ reduction in the treatment of CKD.

\section{Introduction}

Chronic kidney disease (CKD) is an important public health problem, affecting $10-15 \%$ of the adult general population. CKD has a negative effect on cardiac function and frequently leads to anomalies in left ventricular (LV) structure and function. Cardiovascular disease-related mortality is the most common cause of mortality in patients with CKD (1-5). LV diastolic dysfunction, characterized by abnormalities of ventricular filling, including decreased diastolic distensibility and impaired relaxation, is a very common structural abnormality in patients with CKD and is independently associated with morbidity and mortality $(2,3)$. Previous studies have shown that LV function deterioration in CKD patients progresses in a predictable fashion, with $\mathrm{LV}$ diastolic dysfunction usually preceding LV systolic dysfunction (5-7). These findings suggest that maintaining LV diastolic function may be critical for preventing cardiac failure in CKD patients $(6,7)$.

CKD frequently coexists with traditional cardiovascular risk factors, hypertension (HP) being the most common. HP can be either a cause or a consequence of CKD. Specifically, HP is known to play an important role in causing LV diastolic dysfunction. Several trials have demonstrated the benefit of blood pressure (BP) control in slowing the progression of kidney disease and improving clinical outcomes, particularly in patients with CKD stage $\geq 3(4,8)$; however, the mechanisms involved remain unknown. Diastolic dysfunction is considered as an important pathophysiological intermediate to heart failure and represents a attractive target for cardiovascular disease prevention (4-7). However, to the best of our knowledge, the impact of antihypertensive treatment on LV diastolic function has never been analyzed in CKD patients.

Newly developed two-dimensional speckle tracking echocardiography (2DSTE) is based on tracking of the speckles produced by the interaction of ultrasound with the ventricular structures and quantitatively analyzes global and regional myocardial motion. Global diastolic strain rate (SR) 
measurements, averaged from all LV segmental SRs at the same time, have been validated to be accurate in the assessment of diastolic function and advantageous over the traditional tissue Doppler approach $(9,10)$. In light of this evidence, 2DSTE was chosen for use in the current study to evaluate the effect of antihypertensive treatment on LV diastolic function in patients with CKD.

\section{Materials and methods}

Study population. Initially, 172 consecutive patients with newly diagnosed and untreated hypertension with decreased estimated glomerular filtration rate (eGFR) or elevated albuminuria levels were recruited from the outpatient department of Wuxi People's Hospital Affiliated to Nanjing Medical University (Wuxi, China), among whom 152 patients met standard clinical criteria for CKD (11). BP was measured in a sitting position (measurements were made after a 5-min rest in a sitting position with a certified mercury sphygmomanometer; an average of three measurements made at an interval of $\geq 2$ min was used in the analysis). Patients underwent clinical assessment that included an evaluation of their symptoms and physical condition prior to enrollment. HP was diagnosed and treated in accordance with the Seventh Report of the Joint National Committee on the Prevention, Detection, Evaluation and Treatment of High Blood Pressure; the goal of antihypertensive treatment is to attain a $\mathrm{BP}<130 / 80 \mathrm{mmHg}$ (12). Antihypertensive agents, namely $\beta$-blockers, diuretics, calcium channel blockers (CCBs), angiotensin receptor blockers (ARBs) and angiotensin converting enzyme inhibitors (ACEIs), were titrated to the maximal tolerated dose and used in combination when the BP goal was not reached. BP treatment was checked every 2 weeks and continued for 6 months. The following indicators were used as exclusion criteria: clinically significant coronary artery disease, any valvular diseases, atrial fibrillation, anticipated dialysis initiation within 6 months, LV ejection fraction (EF) $<50 \%$ and poor-quality imaging on echocardiography. A total of 18 patients were excluded on the basis of these exclusion criteria; therefore, the final study population consisted of 134 hypertensive patients with stable CKD (73 males and 61 females; mean age, 50.8 \pm 11.5 years). Blood samples were obtained from all participants and laboratory tests were performed to determine the levels of hemoglobin, fasting glucose, total cholesterol, low-density lipoprotein cholesterol (LDL), triglyceride and B-type natriuretic peptide (BNP). eGFR was calculated by the Modification of Diet in Renal Disease equation (13). The final protocol was approved by the Human Ethics Committee of Wuxi People's Hospital Affiliated to Nanjing Medical University. Written informed consent was obtained from all subjects. All patients were treated with antihypertensive drugs and underwent two separate transthoracic echocardiographic exams at baseline and after 6 months of therapy.

Echocardiographic evaluation. Baseline and follow-up echocardiographic exams were performed using a Vivid 7 ultrasound system (GE Medical Systems, Milwaukee, WI, USA). Two-dimensional measurements were performed according to the American Society of Echocardiography recommenda- tions (14) and included LV ejection fraction (LVEF) by the biplane method of discs, maximal left atrial (LA) volume by the method of discs and LV mass (LVM) calculated using the Devereux formula. Maximal LA volume and LVM were indexed to body surface area. Tissue Doppler imaging at the septal side of the mitral annulus was used to specify early diastolic ( $\left.E^{\prime}\right)$ mitral annular velocity. Mitral inflow measurements included peak early (E) and peak late (A) velocities and the deceleration time (DT) of E (14). The E/A and E/E' ratios were subsequently calculated. Three cardiac cycles were measured and averaged for all Doppler measurements.

Grayscale images of apical views were obtained with frame rates $>80 \mathrm{~Hz}$ for strain analysis by 2DSTE (Fig. 1). Recordings were processed with acoustic-tracking software (EchoPAC PC version 110.0.0, GE Healthcare) allowing off-line semi-automated speckle-based strain analyses. Longitudinal LV strain rates were measured by 2DSTE as previously reported $(9,10)$. Peak systolic strain rate $\left(\mathrm{SR}_{\mathrm{SYS}}\right)$, peak strain rate during isovolumetric relaxation period $\left(\mathrm{SR}_{\mathrm{IVR}}\right)$ and early diastole $\left(\mathrm{SR}_{\mathrm{E}}\right)$ were calculated by averaging the values of each of the 18 segments, which were derived from the 6 segments of each of the 3 apical views (2-chamber, 4-chamber, and apical long-axis views). The ratio of $\mathrm{E}$ and $\mathrm{SR}_{\mathrm{IVR}}$ was calculated. All measurements of heart structure and performance were averaged over 3 cardiac cycles.

Intraobserver and interobserver variation. A total of 15 randomly selected subjects were independently assessed by two echocardiologists to identify variability between and within observers in the measurement of 2DSTE parameters.

Statistical analysis. Distribution of data was assessed using a one-sample Kolmogorov-Smirnov test. Data are reported as mean \pm standard deviation (SD) for normally distributed continuous variables, median (quartile 1-quartile 3) for skew-distributed continuous variables, and frequencies for categorical variables. For numerical variables, an independent sample t-test and the Mann-Whitney U test were used for inter-group comparisons. A comparison of the clinical and echocardiographic variables before and after treatment was performed by paired sample t-test or Wilcoxon signed-rank test. Spearman's correlation analysis was used to assess the strength of the association between variables with non-normal distributions. Multivariate linear regression analyses (backward) were performed with significant variables in univariate analysis to determine the independence. Inter- and intra-observer agreements were assessed with intraand inter-class correlation coefficients. For all tests, a P-value $<0.05$ was considered significant. All statistical analyses were performed using SPSS statistical software, version 15.0 (SPSS Inc., Chicago, IL, USA).

\section{Results}

Characteristics of the study population. A cohort of 134 non-dialyzed CKD patients was included (73 males and 61 females; mean age, $50.8 \pm 11.5$ years). Of these participants, 36 patients $(26.9 \%)$ had stage 1 CKD, 38 patients $(28.4 \%)$ had stage 2 CKD, 44 patients $(32.8 \%)$ had stage 4 CKD and 16 patients $(11.9 \%)$ had stage 5 CKD. Subjects were categorized into two groups based on the CKD stage. These were group I 
Table I. Baseline and follow-up demographic and clinical variables.

\begin{tabular}{|c|c|c|c|c|c|c|}
\hline \multirow[b]{2}{*}{ Characteristics } & \multicolumn{2}{|c|}{ Total $(n=134)$} & \multicolumn{2}{|c|}{ Group I $(\mathrm{n}=74)$} & \multicolumn{2}{|c|}{ Group II $(n=60)$} \\
\hline & Baseline & Follow-up & Baseline & Follow-up & Baseline & Follow-up \\
\hline Age (years) & $50.8 \pm 11.5$ & & $48.8 \pm 11.6$ & & $52.9 \pm 11.2$ & \\
\hline Male/female (n/n) & $73 / 61$ & & $40 / 34$ & & $33 / 27$ & \\
\hline $\operatorname{BSA}\left(m^{2}\right)$ & $1.77 \pm 0.35$ & $1.77 \pm 0.35$ & $1.76 \pm 0.37$ & $1.76 \pm 0.36$ & $1.78 \pm 0.33$ & $1.77 \pm 0.34$ \\
\hline Systolic BP (mmHg) & $154.6 \pm 7.6$ & $124.0 \pm 7.3^{\mathrm{a}}$ & $150.4 \pm 5.6$ & $122.9 \pm 6.5^{\mathrm{a}}$ & $159.8 \pm 6.4^{b}$ & $125.4 \pm 8.0^{\mathrm{a}, \mathrm{b}}$ \\
\hline Diastolic BP (mmHg) & $92.6 \pm 10.2$ & $74.6 \pm 10.4^{\mathrm{a}}$ & $90.5 \pm 9.3$ & $73.8 \pm 9.3^{\mathrm{a}}$ & $94.9 \pm 10.7^{\mathrm{b}}$ & $75.4 \pm 11.5^{\mathrm{a}}$ \\
\hline Heart rate (bpm) & $72.7 \pm 6.8$ & $70.7 \pm 6.9$ & $72.0 \pm 6.6$ & $70.2 \pm 7.0$ & $73.5 \pm 7.0$ & $71.3 \pm 6.7$ \\
\hline Total cholesterol (mmol/l) & $4.7 \pm 1.2$ & $4.4 \pm 0.8$ & $4.4 \pm 1.0$ & $4.3 \pm 0.8$ & $4.6 \pm 1.0$ & $4.4 \pm 0.9$ \\
\hline LDL cholesterol (mmol/l) & $2.3 \pm 0.7$ & $2.2 \pm 0.6$ & $2.3 \pm 0.6$ & $2.2 \pm 0.7$ & $2.4 \pm 0.7$ & $2.2 \pm 0.6$ \\
\hline Hemoglobin (g/l) & $116.7 \pm 23.9$ & $117.7 \pm 22.5$ & $120.0 \pm 21.5$ & $118.2 \pm 21.9$ & $113.0 \pm 25.9$ & $117.1 \pm 23.3$ \\
\hline Glucose (mmol/l) & $6.4 \pm 1.4$ & $6.7 \pm 1.7$ & $6.4 \pm 1.5$ & $6.3 \pm 1.4$ & $6.7 \pm 1.7$ & $6.5 \pm 1.8$ \\
\hline eGFR $\left(\mathrm{ml} / \mathrm{min} / 1.73 \mathrm{~m}^{2}\right)$ & $61.8 \pm 24.3$ & $65.9 \pm 24.1$ & $81.2 \pm 10.8$ & $84.7 \pm 11.7$ & $37.9 \pm 11.8^{b}$ & $42.7 \pm 11.4^{\mathrm{a}, \mathrm{b}}$ \\
\hline $\mathrm{BNP}(\mathrm{pg} / \mathrm{ml})$ & $205(179,265)$ & $172(155,200)^{\mathrm{a}}$ & $179(172,190)$ & $158(148,165)^{\mathrm{a}}$ & $272(242,287)^{\mathrm{b}}$ & $202(195,212)^{a, b}$ \\
\hline Smoking history, n (\%) & $25(18.7)$ & & $15(20.2)$ & & $10(16.7)$ & \\
\hline Diabetes mellitus, n (\%) & $50(37.3)$ & & $27(36.5)$ & & $23(38.3)$ & \\
\hline Dyslipidemia, n (\%) & $56(41.8)$ & & $30(40.5)$ & & $26(43.3)$ & \\
\hline ARBs or ACEIs, n (\%) & $61(45.5)$ & & $38(51.4)$ & & $28(38.3)$ & \\
\hline$\beta$-blockers, n (\%) & $58(43.3)$ & & $27(36.5)$ & & $31(51.7)$ & \\
\hline CCBs, n (\%) & $95(70.9)$ & & $48(64.8)$ & & $47(73.4)$ & \\
\hline Diuretics, n (\%) & $49(74.6)$ & & $51(68.9)$ & & $49(81.7)$ & \\
\hline
\end{tabular}

BSA, body surface area; BP, blood pressure; bpm, beats per minute; LDL, low-density-lipoprotein; eGFR, estimated glomerular filtration rate; BNP, B-type natriuretic peptide; ACEIs, angiotensin converting enzymes inhibitors; ARBs, angiotensin receptor blockers; CCBs, calcium channel blockers. ${ }^{a} \mathrm{P}<0.05$ compared with baseline; ${ }^{b} \mathrm{P}<0.05$ compared with group I. Data are presented as mean \pm standard deviation for normally distributed continuous variables, median (quartile 1-quartile 3) for skew-distributed continuous variables and frequencies for categorical variables.

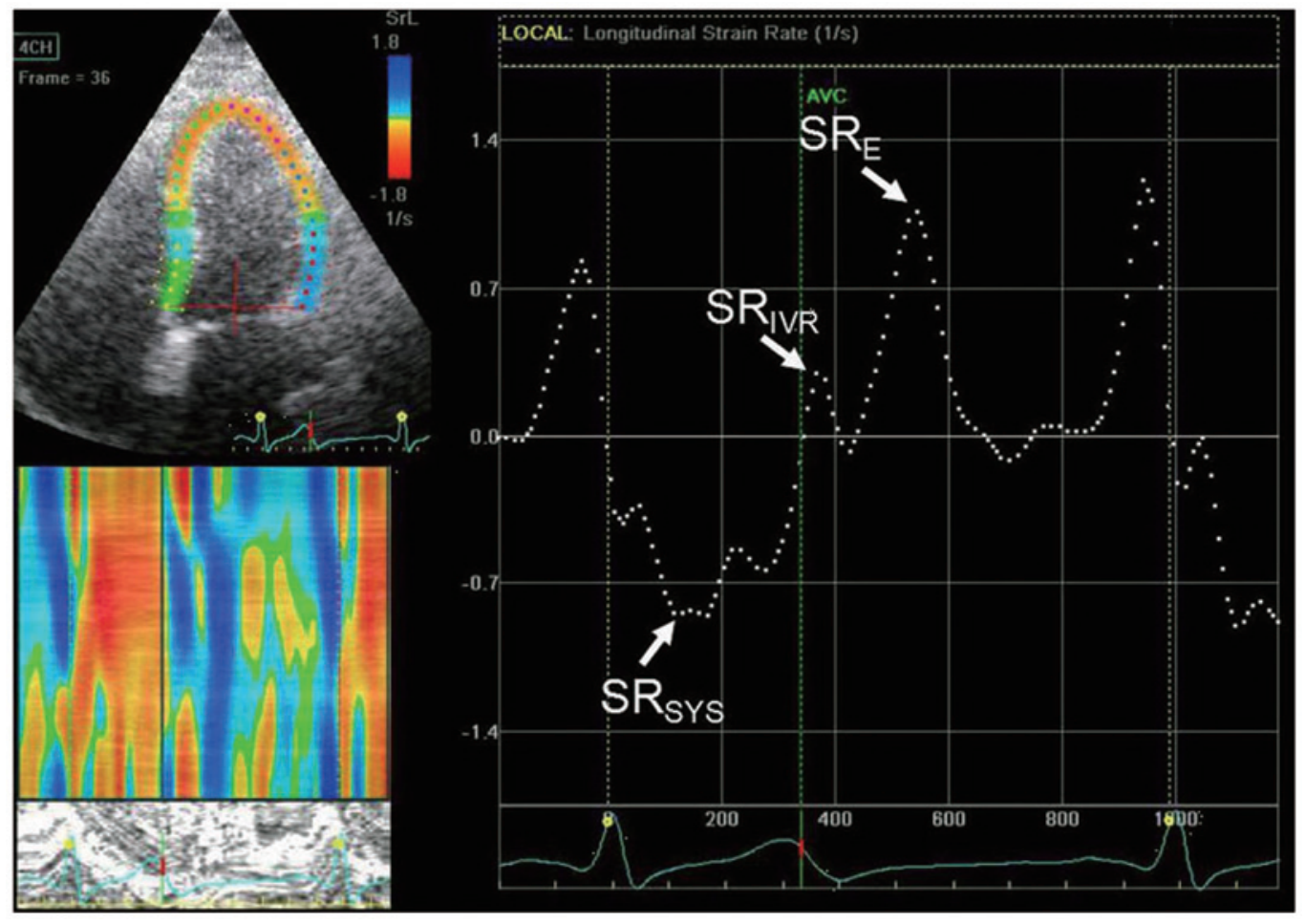

Figure 1. Longitudinal global strain rate of the left ventricle. AVC, aortic valve closure; $\mathrm{SR}_{\mathrm{SYS}}, \mathrm{LV}$ peak systolic strain rate; $\mathrm{SR}_{\mathrm{IVR}}, \mathrm{LV}$ peak strain rate during the isovolumetric relaxation period; $\mathrm{SR}_{\mathrm{E}}, \mathrm{LV}$ peak strain rate during early diastole. 
Table II. Baseline and follow-up echocardiographic parameters in the study population.

\begin{tabular}{|c|c|c|c|c|c|c|}
\hline \multirow[b]{2}{*}{ Parameters } & \multicolumn{2}{|c|}{ Total $(n=134)$} & \multicolumn{2}{|c|}{ Group I $(n=74)$} & \multicolumn{2}{|c|}{ Group II $(n=60)$} \\
\hline & Baseline & Follow-up & Baseline & Follow-up & Baseline & Follow-up \\
\hline LA volume index $\left(\mathrm{ml} / \mathrm{m}^{2}\right)$ & $36.2 \pm 5.9$ & $33.1 \pm 5.9^{\mathrm{a}}$ & $35.7 \pm 5.7$ & $32.8 \pm 5.9^{\mathrm{a}}$ & $36.8 \pm 6.0$ & $33.5 \pm 5.8^{\mathrm{a}}$ \\
\hline LV end-diastolic dimension (mm) & $49.6 \pm 2.8$ & $49.2 \pm 2.7$ & $48.9 \pm 2.7$ & $48.5 \pm 2.9$ & $50.6 \pm 2.8$ & $50.0 \pm 2.6$ \\
\hline $\operatorname{LV} \mathrm{MI}\left(\mathrm{g} / \mathrm{m}^{2}\right)$ & $95.1 \pm 26.7$ & $93.0 \pm 25.7$ & $87.3 \pm 19.0$ & $86.7 \pm 18.7$ & $104.7 \pm 31.6$ & $100.7 \pm 30.7$ \\
\hline LV ejection fraction $(\%)$ & $68.0 \pm 8.9$ & $68.7 \pm 11.4$ & $68.5 \pm 7.5$ & $69.4 \pm 10.0$ & $67.2 \pm 10.3$ & $67.8 \pm 12.9$ \\
\hline Mitral deceleration time (msec) & $208.1 \pm 50.0$ & $212.5 \pm 45.4$ & $210.5 \pm 46.7$ & $214.8 \pm 42.3$ & $205.2 \pm 53.8$ & $209.6 \pm 49.2$ \\
\hline E velocity (m/sec) & $73.4 \pm 28.4$ & $71.0 \pm 22.5$ & $72.9 \pm 33.1$ & $70.1 \pm 12.4$ & $74.1 \pm 21.4$ & $72.2 \pm 31.7$ \\
\hline A velocity (m/sec) & $62.5 \pm 23.9$ & $59.2 \pm 29.7$ & $60.8 \pm 34.2$ & $59.9 \pm 26.2$ & $64.7 \pm 30.6$ & $60.9 \pm 33.7$ \\
\hline $\mathrm{E} / \mathrm{A}$ & $1.2 \pm 0.2$ & $1.3 \pm 0.3$ & $1.2 \pm 0.2$ & $1.3 \pm 0.3$ & $1.2 \pm 0.3$ & $1.3 \pm 0.3$ \\
\hline $\mathrm{E}^{\prime}$ velocity $(\mathrm{m} / \mathrm{sec})$ & $8.4 \pm 3.3$ & $9.9 \pm 3.1^{\mathrm{a}}$ & $8.7 \pm 3.8$ & $10.0 \pm 2.0^{\mathrm{a}}$ & $8.0 \pm 2.4$ & $9.9 \pm 4.0^{\mathrm{a}}$ \\
\hline $\mathrm{E} / \mathrm{E}^{\prime}$ & $9.0 \pm 1.8$ & $8.2 \pm 1.2^{\mathrm{a}}$ & $8.5 \pm 1.5$ & $8.1 \pm 0.9$ & $9.5 \pm 2.0^{\mathrm{b}}$ & $8.2 \pm 1.5^{\mathrm{a}}$ \\
\hline $\mathrm{SR}_{\mathrm{SYS}}\left(\mathrm{sec}^{-1}\right)$ & $-0.80 \pm 0.06$ & $-0.82 \pm 0.07$ & $-0.81 \pm 0.06$ & $-0.83 \pm 0.06$ & $-0.80 \pm 0.06$ & $-0.81 \pm 0.09$ \\
\hline $\mathrm{SR}_{\mathrm{IVR}}\left(\mathrm{sec}^{-1}\right)$ & $0.23 \pm 0.10$ & $0.42 \pm 0.10^{\mathrm{a}}$ & $0.30 \pm 0.07$ & $0.43 \pm 0.08^{a}$ & $0.13 \pm 0.03^{\mathrm{b}}$ & $0.41 \pm 0.11^{\mathrm{a}}$ \\
\hline $\mathrm{SR}_{\mathrm{E}}\left(\mathrm{sec}^{-1}\right)$ & $0.58 \pm 0.25$ & $1.07 \pm 0.24^{\mathrm{a}}$ & $0.76 \pm 0.17$ & $1.08 \pm 0.20^{\mathrm{a}}$ & $0.34 \pm 0.13^{\mathrm{b}}$ & $1.04 \pm 0.27^{\mathrm{a}}$ \\
\hline $\mathrm{E} / \mathrm{SR}_{\mathrm{IVR}}(\mathrm{m})$ & $3.8 \pm 1.8$ & $1.7 \pm 0.4^{\mathrm{a}}$ & $2.3 \pm 0.7$ & $1.7 \pm 0.2^{\mathrm{a}}$ & $5.6 \pm 1.0^{\mathrm{b}}$ & $1.8 \pm 0.5^{\mathrm{a}}$ \\
\hline
\end{tabular}

LA, left atrial; LV, left ventricular; MI, mass index; E, mitral early diastolic velocity; A, mitral late diastolic velocity; E', early diastolic mitral annular velocity; $\mathrm{SR}_{\mathrm{SYS}}$, average of peak $\mathrm{LV}$ systolic strain rate; $\mathrm{SR}_{\mathrm{IVR}}$, average of peak $\mathrm{LV}$ strain rate during isovolumetric relaxation; $\mathrm{SR}_{\mathrm{E}}$, average of peak LV strain rate during early diastole. ${ }^{a} \mathrm{P}<0.05$ compared with baseline; ${ }^{b} \mathrm{P}<0.05$ compared with group I. Data are presented as mean \pm standard deviation.

Table III. Comparison of changes in diastolic parameters and plasma BNP levels between the two groups.

\begin{tabular}{lccc}
\hline Parameters & Group I $(\mathrm{n}=74)$ & Group II $(\mathrm{n}=60)$ & P-value \\
\hline$\Delta \mathrm{LA}$ volume index $\left(\mathrm{ml} / \mathrm{m}^{2}\right)$ & $-2.7(-3.0,-2.6)$ & $-3.2(-3.7,-2.6)$ & 0.17 \\
Deceleration time $(\mathrm{msec})$ & $-8.0(-41.2,27.2)$ & $-6.0(-34.8,19.5)$ & 0.61 \\
$\Delta \mathrm{E} / \mathrm{A}$ & $0.04(-0.13,0.17)$ & $-0.01(-0.14,0.17)$ & 0.81 \\
$\Delta \mathrm{E} / \mathrm{E}^{\prime}$ & $-0.01(-0.78,0.16)$ & $-1.40(-1.83,-0.50)$ & $<0.01$ \\
$\Delta \mathrm{SR}_{\mathrm{IVR}}\left(\mathrm{sec}^{-1}\right)$ & $0.15(0.10,0.19)$ & $0.31(0.27,0.34)$ & $<0.01$ \\
$\Delta \mathrm{SR} \mathrm{E}_{\left(\mathrm{sec}^{-1}\right)}$ & $0.35(0.25,0.47)$ & $0.75(0.69,0.84)$ & $<0.01$ \\
$\Delta \mathrm{E} / \mathrm{SR}$ & $-0.39(-0.45,-0.35)$ & -0.01 \\
$\Delta \mathrm{BNP}(\mathrm{pg} / \mathrm{ml})$ & $-21(-28,-17)$ & $-71(-78,-48)$ & $<0.01$ \\
\hline
\end{tabular}

LA, left atrial; E, mitral early diastolic velocity; A, mitral late diastolic velocity; E', early diastolic mitral annular velocity; $\mathrm{SR}_{\mathrm{IVR}}$, average of peak LV strain rate during isovolumetric relaxation; $\mathrm{SR}_{\mathrm{E}}$, average of peak LV strain rate during early diastole; BNP, B-type natriuretic peptide. Data are reported as median (quartile 1-quartile 3).

(CKD stage 1 or $2 ; n=74)$ and group II (CKD stage $\geq 3 ; n=60)$. Table I presents a detailed list of demographic and clinical variables at baseline and follow-up. Following antihypertensive treatment, 69 patients achieved their target BP in group I (93.2\%), and 53 patients in group II (88.3\%). Notably, participants in group II at study entry were older, had higher systolic $\mathrm{BP}$ (SBP) and diastolic BP (DBP), as well as higher BNP levels; however, SBP, DBP and the level of BNP declined from baseline to follow-up in the two groups.

Baseline and follow-up echocardiographic results. Table II lists comprehensive list of echocardiographic measurements at baseline and follow-up. LVEF and $\mathrm{SR}_{\mathrm{SYS}}$ at baseline and follow-up were similar across the two groups. Compared with group I, higher $\mathrm{E} / \mathrm{E}^{\prime}$ and $\mathrm{E} / \mathrm{SR}_{\mathrm{IVR}}$ ratios, and lower $\mathrm{SR}_{\mathrm{IVR}}$ and $\mathrm{SR}_{\mathrm{E}}$ indicated more severe baseline diastolic dysfunction in group II. Over the study period, the E/E' ratio was similar between baseline and follow-up in group I, but was decreased at follow-up in group II; however, there were no significant differences in E velocity, A velocity, E/A ratio or DT. Although $\mathrm{SR}_{\mathrm{IVR}}$ and $\mathrm{SR}_{\mathrm{E}}$ improved from baseline to follow-up in both groups, the ratio of $\mathrm{E} / \mathrm{SR}_{\mathrm{IVR}}$ decreased. As shown in Table III, the patients in group II were more likely to demonstrate improvements in diastolic speckle-tracking parameters 
Table IV. Clinical predictors for the difference of $\mathrm{SR}_{\mathrm{IVR}}$ between the baseline and follow-up using univariate and multivariate linear regression analyses.

\begin{tabular}{|c|c|c|c|c|c|c|}
\hline \multirow[b]{2}{*}{ Variables } & \multicolumn{3}{|c|}{ Univariate } & \multicolumn{3}{|c|}{ Multivariate } \\
\hline & B & $95 \% \mathrm{CI}$ & P-value & B & $95 \% \mathrm{CI}$ & $\mathrm{P}$-value \\
\hline Age & 0.23 & $0.09,0.37$ & $<0.01$ & & & \\
\hline Baseline CKD stage & 8.78 & $7.78,9.78$ & $<0.01$ & 4.11 & $1.79,6.44$ & $<0.01$ \\
\hline$\Delta \mathrm{eGFR}$ & 0.17 & $-0.02,0.35$ & 0.04 & & & \\
\hline Baseline systolic BP & 0.71 & $0.54,0.89$ & $<0.01$ & 0.15 & $0.02,0.28$ & 0.02 \\
\hline$\Delta$ Systolic BP & 0.69 & $0.56,0.82$ & $<0.01$ & 0.20 & $0.08,0.33$ & $<0.01$ \\
\hline Baseline diastolic BP & 0.16 & $-0.02,0.33$ & 0.03 & & & \\
\hline$\Delta$ Diastolic BP & 2.04 & $1,35,2.73$ & $<0.01$ & & & \\
\hline Baseline LVMI & 0.09 & $0.02,0.15$ & $<0.01$ & & & \\
\hline Baseline $\mathrm{SR}_{\mathrm{IVR}}$ & -0.75 & $-0.86,-0.64$ & $<0.01$ & -0.26 & $-0.44,-0.08$ & $<0.01$ \\
\hline
\end{tabular}

CI, confidence interval; CKD, chronic kidney disease; eGFR, estimated glomerular filtration rate; BP, blood pressure; LVMI, left ventricular mass index; $\mathrm{SR}_{\mathrm{IVR}}$, average of peak $\mathrm{LV}$ strain rate during isovolumetric relaxation.

following treatment compared with those in group I. Plasma levels of BNP, as a biomarker of diastolic function, decreased throughout the study; however, the reduction was greater in group II. Therefore, these analyses indicate an association between the plasma BNP levels and echocardiographic parameters.

Association between BNP levels and echocardiographic parameters. In groups I and II, the BNP level was correlated with $\mathrm{SR}_{\text {IVR }}(\mathrm{r}=-0.77, \mathrm{P}<0.01), \mathrm{E}_{\mathrm{SSR}} \mathrm{IVR}_{\mathrm{R}}(\mathrm{r}=0.69, \mathrm{P}<0.01), \mathrm{SR}_{\mathrm{E}}$ $(\mathrm{r}=-0.68, \mathrm{P}<0.01), \mathrm{E} / \mathrm{E}^{\prime}(\mathrm{r}=0.53, \mathrm{P}<0.01)$ and LA volume index $(\mathrm{LAVI})(\mathrm{r}=0.47, \mathrm{P}<0.01)$ at baseline. The differences $(\Delta)$ of clinical and echocardiographic parameters prior to and following treatment were determined by subtracting the values at follow-up from the values at baseline. There were significant correlations between $\triangle \mathrm{BNP}$ and $\triangle \mathrm{SR}_{\mathrm{IVR}}(\mathrm{r}=-0.73$, $\mathrm{P}<0.01), \Delta \mathrm{E} / \mathrm{SR}_{\mathrm{IVR}}(\mathrm{r}=0.64, \mathrm{P}<0.01), \Delta \mathrm{SR}_{\mathrm{E}}(\mathrm{r}=-0.66, \mathrm{P}<0.01)$, $\Delta \mathrm{E} / \mathrm{E}^{\prime}(\mathrm{r}=0.57, \mathrm{P}<0.01)$ and $\Delta \mathrm{LAVI}(\mathrm{r}=0.51, \mathrm{P}<0.01)$. Among these parameters, $\mathrm{SR}_{\mathrm{IVR}}$ and $\Delta \mathrm{SR}_{\mathrm{IVR}}$ presented the highest correlation coefficient.

Predictors of $\triangle S R_{I V R}$. To control for potential confounding variables in the data, univariate and multivariate linear regression analyses of $\Delta \mathrm{SR}_{\mathrm{IVR}}$ were used to evaluate potential predictive factors for change of diastolic function. In univariate analyses, it was found that age, baseline CKD stage, SBP, DBP, LVMI, $\triangle \mathrm{SBP}$ and $\triangle \mathrm{DBP}$ each were significantly associated with $\Delta \mathrm{SR}_{\mathrm{IVR}}$ (Table IV). On multivariable analysis, baseline CKD stage, SBP and $\triangle$ SBP were positively associated with $\Delta \mathrm{SR}_{\mathrm{IVR}}(\mathrm{P}<0.01)$, and baseline $\mathrm{SR}_{\mathrm{IVR}}$ was inversely associated with $\triangle \mathrm{SR}_{\mathrm{IVR}}(\mathrm{P}<0.01)$.

Reproducibility. The interobserver correlation coefficients [95\% confidence interval (CI)] were good for $\mathrm{SR}_{\text {IVR }}[0.93$ (0.93-0.99)] and $\mathrm{SR}_{\mathrm{E}}$ [0.97 (0.91-0.99)]. The intraobserver correlation coefficients $(95 \% \mathrm{CI})$ were also good for $\mathrm{SR}_{\mathrm{IVR}}$ [0.98 (0.95-0.99)] and $\mathrm{SR}_{\mathrm{E}}$ [0.96 (0.89-0.98)].

\section{Discussion}

To the best of our knowledge, this is the first study to demonstrate that LV diastolic function improves with antihypertensive treatment in patients with CKD using 2DSTE. Notably, antihypertensive treatment was particularly efficacious among patients with CKD stage $\geq 3$.

$\mathrm{E} / \mathrm{E}^{\prime}$ has been shown to be useful in predicting elevated LV filling pressures in clinical studies; however, E/E' has a significant gray zone and is less reliable in preserving LVEF $>50 \%$ due to several factors $(9,15)$. Firstly, there are well-known limitations of Doppler-based methods such as the angle dependency, which has the potential for significant errors with angulations $>20^{\circ}$. Secondly, regional wall motion abnormalities in the sampling region may lead to low annular velocities on tissue Doppler despite near normal LV relaxation. Thirdly, another important limitation of this approach is the potential effect of LA pressure $(9,15,16)$. Since $E^{\prime}$ occurs during the early phase of LV filling, not only LV relaxation, but also LA pressure has an important impact on its value. Furthermore, Andersen et al found there was not a strong correlation between changes in $\mathrm{E} / \mathrm{E}^{\prime}$ and changes in LV filling pressure (17). Conversely, the global LV diastolic SR collected using 2DSTE may overcome all the aforementioned limitations and provide a more complete reflection of overall LV diastolic function than $E / E^{\prime}(9,10,15-17)$. Notably, this measurement reflects the total performance of all LV segments. Therefore, in the present study, the $\mathrm{E} / \mathrm{E}^{\prime}$ ratio was similar between baseline and follow-up in group I, However, significant changes in LV diastolic performance over the study period were revealed following 2DSTE evaluation in these patients.

The BNP assessment used in this study has been validated as a highly sensitive and accurate method for the detection of LV diastolic dysfunction and applied in patients with CKD $(18,19)$. In previous studies concerning HP or CKD, patients with an improvement in LV diastolic function exhibited a reduction in BNP plasma concentration after 
treatment (19-21). The present study found significant changes in BNP concentrations and echocardiographic parameters in patients with CKD following antihypertensive treatment, suggesting an improvement of LV diastolic function. Among these echocardiographic parameters, $\Delta \mathrm{SR}_{\mathrm{IVR}}$ presented the highest correlation with $\triangle \mathrm{BNP}$, suggesting that $\mathrm{SR}_{\mathrm{IVR}}$ might have better diagnostic value than traditional echo indices in detecting changes in $\mathrm{LV}$ diastolic function. $\mathrm{SR}_{\mathrm{IVR}}$ is obtained directly from the ventricular myocardium during the isovolumetric relaxation period (when the mitral valve is closed), meaning that problems related to valvular pathology and LA pressure, which undermine other echocardiographic parameters, are circumvented $(9,22)$.

Patients with CKD have a much greater cardiovascular risk than the general population. Moreover, HP is common in these patients and an important independent risk factor of LV diastolic dysfunction $(2,4,8)$. Previous literature suggests that the mechanism underlying the impairment of LV diastolic function in patients with CKD and HP may be due to increased transmyocardial wall stress, which can produce subendocardial ischemia, thus increasing myocardial stiffness and reducing myocardial deformation in diastole. As BP decreases following medical treatment, LV wall stress also decreases, thus decreasing LV stiffness and improving myocardial diastolic function $(8,15)$. Antihypertensive agents reduce endothelial dysfunction and microvascular disease, which has been shown to contribute to a worsening of cardiovascular risk factors and may also play a role in the pathophysiological process that leads to accelerated cardiovascular disease in patients with CKD (8). This effect may result in greater benefit than that achieved by BP-lowering alone. Studies have reported the benefits of antihypertensive treatment on cardiovascular and renal outcomes in CKD patients, and absolute risk reductions in people with CKD stage $\geq 3$ have been found to be greater than those in people with CKD of stages 1 and $2(4,8)$. The present study found significantly improved LV diastolic function in patients with CKD following 6 months of antihypertensive treatment. Notably, the patients with CKD stage $\geq 3$ were more likely to demonstrate improvements in diastolic parameters than the others. On multivariate analysis, baseline CKD stage and BP were positively associated with $\triangle \mathrm{SR}_{\mathrm{IVR}}$ $(\mathrm{P}<0.01)$, and baseline $\mathrm{SR}_{\mathrm{IVR}}$ was inversely associated with $\triangle \mathrm{SR}_{\mathrm{IVR}}$. These results suggest the importance of $\mathrm{BP}$ reduction in this population, particularly with $\mathrm{CKD}$ stage $\geq 3$, higher $\mathrm{BP}$ and LV diastolic dysfunction.

Several limitations of this study should be considered. The sample was small (134 patients), but the careful selection and recruitment of newly diagnosed and untreated hypertensive individuals is a major challenge in this field. Further confounding the recruitment efforts, patients with severe renal dysfunction and LV systolic dysfunction were excluded from this study. Consequently, the relatively small number of total subjects that was analyzed lessened the power and interpretation of the findings. The patients were not followed for clinical outcomes (such as readmission for clinical events, mortality or stroke), which meant that it was not possible to assess permit associations between the speckle-tracking parameters and outcomes. Furthermore, albuminuria was only assessed at some of the visits during the course of the trial, making it impossible to assess the changes in albuminuria and its interaction with echocardiographic parameters (9). Although the results achieved statistical significance, further follow-up investigation and confirmation in a larger sample are required to validate the findings.

Overall, in the present sample of individuals with CKD, a significant improvement in LV diastolic function was obtained following antihypertensive therapy, which was demonstrated to be more effective in patients with CKD stage $\geq 3$, higher baseline SBP and worse LV diastolic function.

\section{References}

1. McAlister FA, Ezekowitz J, Tonelli M and Armstrong PW: Renal insufficiency and heart failure: prognostic and therapeutic implications from a prospective cohort study. Circulation 109: 1004-1009, 2004.

2. Nardi E, Cottone S, Mulè G, et al: Influence of chronic renal insufficiency on left ventricular diastolic function in hypertensives without left ventricular hypertrophy. J Nephrol 20: 320-328, 2007.

3. Bruch C, Rothenburger M, Gotzmann M, et al: Chronic kidney disease in patients with chronic heart failure - impact on intracardiac conduction, diastolic function and prognosis. Int $\mathrm{J}$ Cardiol 118: 375-380, 2007.

4. Blood Pressure Lowering Treatment Trialists' Collaboration; Ninomiya T, Perkovic V, Turnbull F, et al: Blood pressure lowering and major cardiovascular events in people with and without chronic kidney disease: meta-analysis of randomised controlled trials. BMJ 347: f5680, 2013.

5. Foley RN, Parfrey PS and Sarnak MJ: Clinical epidemiology of cardiovascular disease in chronic renal disease. Am J Kidney Dis 32 (Suppl 3): S112-S119, 1998.

6. Fathi R, Isbel N, Haluska B, et al: Correlates of subclinical left ventricular dysfunction in ESRD. Am J Kidney Dis 41: 1016-1025, 2003.

7. Solomon SD, Janardhanan R, Verma A, et al; Valsartan In Diastolic Dysfunction (VALIDD) Investigators: Effect of angiotensin receptor blockade and antihypertensive drugs on diastolic function in patients with hypertension and diastolic dysfunction: a randomised trial. Lancet 369: 2079-2087, 2007.

8. Heerspink HJ, Ninomiya T, Perkovic V, et al; ADVANCE Collaborative Group: Effects of a fixed combination of perindopril and indapamide in patients with type 2 diabetes and chronic kidney disease. Eur Heart J 31: 2888-2896, 2010.

9. Wang J, Khoury DS, Thohan V, et al: Global diastolic strain rate for the assessment of left ventricular relaxation and filling pressures. Circulation 115: 1376-1383, 2007.

10. Kasner M, Gaub R, Sinning D, et al: Global strain rate imaging for the estimation of diastolic function in HFNEF compared with pressure-volume loop analysis. Eur J Echocardiogr 11: 743-751, 2010.

11. National Kidney Foundation: K/DOQI clinical practice guidelines for chronic kidney disease: evaluation, classification and stratification. Am J Kidney Dis 39 (Suppl 1): S1-S266, 2002.

12. Lenfant C, Chobanian AV, Jones DW and Roccella EJ; Joint National Committee on the Prevention, Detection, Evaluation, and Treatment of High Blood Pressure: Seventh report of the Joint National Committee on the Prevention, Detection, Evaluation and Treatment of High Blood Pressure (JNC 7): resetting the hypertension sails. Hypertension 41: 1178-1179, 2003.

13. Ma YC, Zuo L, Chen JH, et al: Modified glomerular filtration rate estimating equation for Chinese patients with chronic kidney disease. J Am Soc Nephrol 17: 2937-2944, 2006.

14. Lang RM, Bierig M, Devereux RB, et al; Chamber Quantification Writing Group; American Society of Echocardiography's Guidelines and Standards Committee; European Association of Echocardiography: Recommendations for chamber quantification: a report from the American Society of Echocardiography's Guidelines and Standards Committee and the Chamber Quantification Writing Group, developed in conjunction with the European Association of Echocardiography, a branch of the European Society of Cardiology. J Am Soc Echocardiogr 18: 1440-1463, 2005.

15. Alam M, Zhang L, Stampehl M, et al: Usefulness of speckle tracking echocardiography in hypertensive crisis and the effect of medical treatment. Am J Cardiol 112: 260-265, 2013. 
16. Kimura K, Takenaka K, Ebihara A, et al: Speckle tracking global strain rate $\mathrm{E} / \mathrm{E}^{\prime}$ predicts $\mathrm{LV}$ filling pressure more accurately than traditional tissue Doppler E/E'. Echocardiography 29: 404-410, 2012.

17. Andersen MJ, Ersbøll M, Gustafsson F, et al: Exercise-induced changes in left ventricular filling pressure after myocardial infarction assessed with simultaneous right heart catheterization and Doppler echocardiography. Int J Cardiol 168: 2803-2810, 2013

18. Paulus WJ, Tschöpe C, Sanderson JE, et al: How to diagnose diastolic heart failure: a consensus statement on the diagnosis of heart failure with normal left ventricular ejection fraction by the Heart Failure and Echocardiography Associations of the European Society of Cardiology. Eur Heart J 28: 2539-2550, 2007.

19. Tamez H, Zoccali C, Packham D, et al: Vitamin D reduces left atrial volume in patients with left ventricular hypertrophy and chronic kidney disease. Am Heart J 164: 902-909.e2, 2012.
20. Tapp RJ, Sharp A, Stanton AV, et al; ASCOT Investigators: Differential effects of antihypertensive treatment on left ventricular diastolic function: an ASCOT (Anglo-Scandinavian Cardiac Outcomes Trial) substudy. J Am Coll Cardiol 55: 1875-1881, 2010.

21. Aksoy H, Okutucu S, Kaya EB, et al: Clinical and echocardiographic correlates of improvement in left ventricular diastolic function after cardiac resynchronization therapy. Europace 12: 1256-1261, 2010.

22. Van Schinkel LD, Auger D, van Elderen SG, et al: Aortic stiffness is related to left ventricular diastolic function in patients with diabetes mellitus type 1: assessment with MRI and speckle tracking strain analysis. Int J Cardiovasc Imaging 29: 633-641, 2013. 